Identification of novel neutralizing single-chain antibodies against

\title{
vascular endothelial growth factor
} receptor 2

Berrin Erdag, ${ }^{1 *}$ B. Koray Balcioglu, ${ }^{1}$ Aylin Ozdemir Bahadir, ${ }^{1}$ Muge Serhatli, ${ }^{1}$ Omer Kacar, ${ }^{1}$ Aydin Bahar, ${ }^{1}$ Urartu O. S. Seker, ${ }^{2}$ Emel Akgun, ${ }^{3}$ Abdulkadir Ozkan, ${ }^{3}$ Turker Kilic, ${ }^{3,4}$ Candan Tamerler, ${ }^{5}$ and Kemal Baysal, ${ }^{1,6}$

${ }^{1}$ TUBITAK Marmara Research Center, Genetic Engineering and Biotechnology Institute, Gebze, Kocaeli, Turkey

${ }^{2}$ National Nanotechnology Research Center-Institute of Material Science and Nanotechnology, Bilkent University, Turkey

${ }_{3}$ Molecular Neurosurgery Laboratory, Institute of Neurological Sciences, Marmara University, Istanbul, Turkey

${ }^{4}$ Faculty of Medicine, Department of Neurosurgery, Marmara University, Istanbul, Turkey

${ }_{5}^{5}$ Materials Science and Engineering Department, University of Washington, Seattle, WA, USA

${ }^{6}$ Medical Faculty, Department of Biochemistry, Dokuz Eylül University, Izmir, Turkey

\section{Abstract.}

Human vascular endothelial growth factor (VEGF) and its receptor (VEGFR-2/kinase domain receptor [KDR]) play a crucial role in angiogenesis, which makes the VEGFR-2 signaling pathway a major target for therapeutic applications. In this study, a single-chain antibody phage display library was constructed from spleen cells of mice immunized with recombinant human soluble extracellular VEGFR-2/KDR consisting of all seven extracellular domains (SKDR D1-7) to obtain antibodies that block VEGF binding to VEGFR-2. Two specific single-chain antibodies (KDR1.3 and KDR2.6) that recognized human VEGFR-2 were selected; diversity analysis of the clones was performed by BstNI fingerprinting and nucleotide sequencing. The single-chain variable fragments (scFvs) were expressed in soluble form and specificity of interactions between affinity purified scFvs and VEGFR-2 was

(C) 2011 International Union of Biochemistry and Molecular Biology, Inc. Volume 58, Number 6, November/December 2011, Pages 412-422 • E-mail: berrin.erdag@mam.gov.tr confirmed by ELISA. Binding of the recombinant antibodies for VEGFR-2 receptors was investigated by surface plasmon resonance spectroscopy. In vitro cell culture assays showed that KDR1.3 and KDR2.6 scFvs significantly suppressed the mitogenic response of human umbilical vein endothelial cells to recombinant human $\mathrm{VEGF}_{165}$ in a dose-dependent manner, and reduced VEGF-dependent cell proliferation by $60 \%$ and $40 \%$, respectively. In vivo analysis of these recombinant antibodies in a rat cornea angiogenesis model revealed that both antibodies suppressed the development of new corneal vessels $(p<0.05)$. Overall, in vitro and in vivo results disclose strong interactions of KDR1.3 and KDR2.6 scFvs with VEGFR-2. These findings indicate that KDR1.3 and KDR2.6 scFvs are promising antiangiogenic therapeutic agents.

Keywords: antiangiogenic, corneal angiogenesis assay, HUVEC, phage display, single-chain variable fragment (scFv), vascular endothelial growth factor receptor-2 (VEGFR-2)
Abbreviations: AP, alkaline phosphatase; bAVM, human brain arteriovenous malformation; BrdU, bromodeoxyuridine; BSA, bovine serum albumin; CAA, cornea angiogenesis assay; ECGM, endothelial cell growth medium; FBS, fetal bovine serum; HUVECs, human umbilical vein endothelial cells; KDR, kinase domain receptor; NHS, $\mathrm{N}$-hydroxysulfosuccinimide; NRP1 and NRP2, neuropilin 1 and 2; PBS, phosphate-buffered saline; rhVEGF $_{165}$, recombinant human $\mathrm{VEGF}_{165}$; SAMs, self-assembled monolayers; scFv, single-chain variable fragment; SKDR $D_{1}-7$, soluble KDR domains 1 to 7 ; SPR, surface plasmon resonance; TPBS, PBS + 0.1\% (v/v) Tween 20; VEGF, vascular endothelial growth factor; VEGFR, vascular endothelial growth factor receptor; $\mathrm{VH}$, heavy-chain variable domain; $\mathrm{VL}$, light-chain variable domain.

*Address for correspondence: Dr. Berrin Erdag, PhD, TUBITAK Marmara Research Center, Genetic Engineering and Biotechnology Institute, P.O. Box 21, 41470 Gebze, Kocaeli,

Turkey. Tel: + 902626773345 ; Fax: + 902626462309 ; e-mail:

berrin.erdag@mam.gov.tr.

Received 4 May 2011; accepted 23 September 2011

DOI: $10.1002 /$ bab.61

Published online 15 November 2011 in Wiley Online Library

(wileyonlinelibrary.com)

\section{Introduction}

Angiogenesis, the formation of new blood vessels from preexisting ones, is a physiological phenomenon in embryogenesis, wound healing, and the menstruation cycle in the female reproductive system, but it also occurs in pathological states such as rheumatoid arthritis, diabetic retinopathy, solid tumors, hemangioma, psoriasis, and age-related macular degeneration [1],[2]. As a main component of vessel structure, endothelial cells play a pivotal role in angiogenic processes. The activation, proliferation, and migration of these cells result in the formation of a new blood vessel. Their critical role in angiogenesis makes endothelial cells primary targets for angiogenesis activation/inhibition. The "angiogenic switch" is regulated by a tight balance between proangiogenic and antiangiogenic molecules, 
among which vascular endothelial growth factor (VEGF), an endothelial cell-specific mitogen, is the key modulator [3],[4].

Vascular endothelial growth factor acts through vascular endothelial growth factor receptor (VEGFR)-1 (flt-1), VEGFR-2 (kinase domain receptor [KDR]), and VEGFR-3 (flt-4) members of the cell surface receptor-type tyrosine kinase family [5]. Another family of receptors, the neuropilins (NRP1 and NRP2), has also been identified and appears to function as coreceptors to modulate receptor binding without being active in signaling. It has been shown that VEGF-induced proliferation and migration of cells expressing VEGFR-2 are enhanced in the presence of NRP1 [5-7]. Several studies showed that VEGFR-2 (KDR) is crucial for VEGF functioning via mediation of endothelial cell proliferation and chemotaxis [8]. VEGFR-2 (KDR) is expressed at high levels in endothelial cells and hematopoietic cells [9-11]. KDR has seven extracellular immunoglobulin-like domains that function in transmission of signals from the environment into the cytoplasm [12].

Folkman [13] suggested that tumor growth depends on oxygen and energy resources carried by new capillaries that develop from nearby blood vessels and asserted that attempts to block angiogenesis may be an effective approach in inhibiting tumor growth. Later studies demonstrated that antiangiogenic approaches are promising in cancer treatment [14]; in particular, antibodies developed against VEGF have been found to slow tumor growth [15]. An essential role for VEGF in tumor angiogenesis has been demonstrated in animal models, wherein neutralizing VEGF antibodies and dominant-negative VEGF receptors block angiogenesis and inhibit disease progression [14],[16],[17]. Similar studies showed that structures targeting VEGF may be useful in cancer treatment. This concept was demonstrated in a mouse neuroblastoma model using a neutralizing antibody [18]. Another study [19] showed that increasing affinity to neonatal Fc receptor may extend the pharmacokinetic half-life of an antibody. Collectively, these studies have encouraged researchers to develop monoclonal antibodies that are capable of blocking VEGF and its receptors to prevent tumor growth, and VEGF antibodies have recently been approved for clinical use [20].

Monoclonal antibodies are considered the magic bullet for targeted cancer therapy; however, the large size of an intact antibody prevents penetration of the tumor mass [21]. To circumvent this limitation, various studies have demonstrated that phage display technology can be used to identify new recombinant antibody structures [22]. In contrast to whole antibody structures, recombinant antibodies in the form of single-chain variable fragments (scFvs) exhibit rapid blood clearance [23], excellent tumor penetration from the vasculature, and greater tumor-specific effects in animal models [24].

In this study, we identified scFvs that directly bind VEGFR2 and inhibit VEGF-dependent cell proliferation and quantified their receptor-binding affinities. Phage display method was used to construct recombinant single-chain antibodies, which are smaller in molecular size but still retain the VEGF-blocking property of larger antibodies as described in previous study [25]. Two specific single-chain antibodies (KDR1.3 and KDR2.6 scFvs) recognizing the extracellular immunoglobulin-like domains 1-7 of VEGFR-2 were selected from a V-gene phage display library constructed from mice immunized with the commercially available soluble extracellular domains 1-7 of VEGFR-2 (sKDR D1-7; AngioBio, CA, USA). KDR1.3 and KDR2.6 scFvs were characterized at the DNA and protein levels by ELISA, DNA sequencing, and surface plasmon resonance (SPR) spectroscopy. Both antiKDR scFvs bind to sKDR D1-7, block VEGF binding to SKDR D1-7, and show potent inhibition of VEGF-induced cell proliferation in human umbilical vein endothelial cells (HUVECS) by a rat cornea angiogenesis assay (CAA). Our results demonstrated that KDR1.3 and KDR2.6 antibodies could inhibit angiogenesis via interaction with the VEGFR-2 extracellular domain. Thus, the identified recombinant antibodies may have potential to be used as angiogenesis inhibitors.

\section{Materials and methods}

\subsection{Immunization of mice and construction of a scFv antibody phage display library}

For the immunization studies, 7-week-old male Balb/cJ mice were used $(n=3)$. The first injection was done by injecting $300 \mu \mathrm{L}$ of solution containing $150 \mu \mathrm{L}$ phosphate-buffered saline (PBS) and $150 \mu \mathrm{L}$ Freund's complete adjuvant containing $10 \mu \mathrm{g}$ sKDR D1-7 (recombinant human SVEGFR-2 SKDR D17; AngioBio, Del Mar, CA, USA) under the armpit skin of each mouse. In the third week following the first immunization, the same amount of mixture was prepared and injected into using Freund's incomplete adjuvant. After a 1-month rest period following the second immunization, two mice were injected in the tail vein with $150 \mu \mathrm{L}$ PBS containing $10 \mu \mathrm{g}$ SKDR D1-7. Total RNA was extracted from spleen with the EZ-RNA Total RNA Isolation Kit (Biological Industries, Kibbutz Beit Haemek, Israel) 4 days after the last injection. Complementary DNA (cDNA) was generated with the hexamer primer-based standard method [26] and was used as a template for the amplification of immunoglobulin heavy- (VH) and light- (VL) chain variable regions by PCR. $\mathrm{VH}$ variable region amplification was performed in a $50 \mu \mathrm{L}$ reaction volume containing $5 \mu \mathrm{L}$ Taq polymerase buffer $(10 \times), 3 \mu \mathrm{L}$ $\mathrm{MgCl}_{2}(25 \mathrm{mM}), 1 \mu \mathrm{LdNTP} / 10 \mathrm{mM}$ each, $2 \mu \mathrm{L}$ heavy-chain primer 1 and 2 each (Amersham Pharmacia Biotech, Uppsala, Sweden), $2 \mu \mathrm{L}$ template $\mathrm{CDNA}, 1 \mu \mathrm{L}$ Taq polymerase $(1 \mathrm{U} / \mu \mathrm{L}$ ) (Fermentas, Vilnius, Lithuania). VL variable region amplification was performed as VH variable amplification except that $1 \mu \mathrm{L}$ VL primer mix was used. The PCR reactions were purified with the Agarose Gel DNA Extraction Kit (Roche Applied Science, Mannheim, Germany) and used as a template for the generation of scFv.

The generation of the scFv was performed in two steps. In the first step, $5 \mu \mathrm{L}$ Taq polymerase buffer $(10 \times), 3 \mu \mathrm{L}$ $\mathrm{MgCl}_{2}(25 \mathrm{mM}), 1 \mu \mathrm{L} \mathrm{dNTP} / 10 \mathrm{mM}$ each, $3 \mu \mathrm{L} \mathrm{VH} \mathrm{PCR} \mathrm{product}$ (100 ng/ $\mu \mathrm{L}$ ), $3 \mu \mathrm{LVL}$ PCR product (100 $\mathrm{ng} / \mu \mathrm{L}$ ), $4 \mu \mathrm{L}$ linker primer (Amersham Pharmacia), and $1 \mu \mathrm{L}$ Taq polymerase $(1 \mathrm{U} / \mu \mathrm{L})$ (Fermentas) were combined in a $50 \mu \mathrm{L}$ reaction volume. After seven cycles of 1 and $4 \mathrm{Min}$ at 94 and $63^{\circ} \mathrm{C}$, respectively, scFv amplification reaction mix was added $\left(34 \mu \mathrm{L} \mathrm{dH}_{2} \mathrm{O}, 5 \mu \mathrm{L}\right.$ Taq polymerase buffer $10 \times, 3 \mu \mathrm{L} \mathrm{MgCl}_{2} 25 \mathrm{mM}, 1 \mu \mathrm{L} \mathrm{dNTP} / 10 \mathrm{mM}$ each, $4 \mu \mathrm{L}$ RS primer mixture Amersham Pharmacia, $1 \mu \mathrm{L}$ Taq polymerase $1 \mathrm{U} / \mu \mathrm{L}$ Fermentas). Then, a second PCR was performed in 25 cycles $\left(94^{\circ} \mathrm{C}\right.$ for $1 \mathrm{Min}, 55^{\circ} \mathrm{C}$ for $2 \mathrm{Min}, 72^{\circ} \mathrm{C}$ for $2 \mathrm{Min})$. ScFv PCR products were analyzed by $1.2 \%$ agarose gel 
electrophoresis. Assembled ScFv DNA was ligated into pDUCK1 using Sfil/Notl restriction sites and transferred into Echerichia coli TG1. Transformant colonies were scraped and stored at $-70^{\circ} \mathrm{C}$ as library stock.

\subsection{Selection of SKDR D1-7-specific recombinant phages}

The library stock was rescued with M13Ko7 helper phage. The phage preparation was precipitated in $4 \%$ polyethylene glycol $6000 / 0.5 \mathrm{M} \mathrm{NaCl}$ and resuspended in PBS $\left(3.2 \mathrm{mM} \mathrm{Na}_{2} \mathrm{HPO}_{4} \times\right.$ $2 \mathrm{H}_{2} \mathrm{O}, 1.4 \mathrm{mM} \mathrm{KH}_{2} \mathrm{PO}_{4}, 2.7 \mathrm{mM} \mathrm{KCl}, 137 \mathrm{mM} \mathrm{NaCl}, \mathrm{pH} 7.4$ ).

Selection of VEGFR-2-binding recombinant antibodies was performed according to Smith and Scott [27]. In this work, $250 \mathrm{ng}$ of sKDR D1-7 was incubated overnight in immunotubes $(75 \times$ $12 \mathrm{~mm}^{2}$, Maxisorb; Nunc, Roskilde, Denmark). The tube was blocked (PBS $+1 \%$ bovine serum albumin BSA; Roche) for $1 \mathrm{H}$ and washed six times with TPBS (PBS $+0.1 \% \mathrm{v} / \mathrm{v}$ Tween-20). Then, $10^{11}$ phage containing the scFv library was added in TPBS. After $2 \mathrm{H}$ incubation at room temperature, nonbinding phages were discarded by washing 30 times with TPBS and then 30 times with PBS. The phages were eluted with elution buffer (o.2 M Glycine pH 2.2, $1 \mathrm{mg} / \mathrm{mL} \mathrm{BSA}$; Roche) and the eluate was neutralized with $75 \mu \mathrm{L} 1 \mathrm{M}$ Tris- $\mathrm{HCl}(\mathrm{pH}$ 9.1). The eluted phages were quantified by tritration and then amplified for the second biopanning step. After the third biopanning step, colonies were picked for further ELISA experiments.

\subsection{Selecting phage-displayed recombinant antibodies that bind SKDR D1-7 by phage ELISA} Infective phages were obtained from bacteria containing the scFv genes. Infective phages were used in a phage ELISA. Each well of a 96-well ELISA plate (BD Falcon, San Diego, CA, USA) was coated with $500 \mathrm{ng}$ SKDR D $1-7$ at $4^{\circ} \mathrm{C}$ overnight. The next day, wells were washed three times with TPBS $(0.1 \%$ Tween 20 in PBS) and blocked for $1 \mathrm{H}$ with TPBS containing $1 \%$ BSA. Wells were washed three times with TPBS and incubated for $2 \mathrm{H}$ with $10^{11}$ infective phages. Wells were washed six times with TPBS and 1:1,000 diluted anti-M13 horseradish peroxidase (HRP)-conjugated antibodies (Pharmacia, Uppsala, Sweden) were used as secondary antibodies. The binding signal was determined with the ELISA reader (Bio-Rad Laboratories, Richmond, CA, USA) by detecting the absorbance $A_{405}$ after $1 \mathrm{H}$ of incubation with ABTS substrate (Pharmacia Biotech, Little Chalfont Buckinghamshire, England).

\subsection{Colony $P C R$ and DNA fingerprinting}

The presence of the SCFV gene in bacterial colonies was determined by colony PCR. Bacteria were suspended in $15 \mu \mathrm{L}$ distilled water. Tubes were incubated at $95^{\circ} \mathrm{C}$ for 3 Min and centrifuged. The upper fluid was used as template for PCR. Primer 458, 5'-TTTTGTCGTCTTTCCAGACGTT-3', and primer 459, 5'-TATGACCATGATTACGCCAAG-3', were used as forward and reverse primers. The PCR cycling program was $5 \mathrm{Min}$ at $94^{\circ} \mathrm{C}$ then 30 cycles of $1 \mathrm{Min}$ at $94^{\circ} \mathrm{C}, 2 \mathrm{Min}$ at $55^{\circ} \mathrm{C}, 2 \mathrm{Min}$ at $72^{\circ} \mathrm{C}$, and an elongation step of $10 \mathrm{Min}$ at $72^{\circ} \mathrm{C}$. The PCR products were digested with BstNI enzyme for PCR screening [28].

\subsection{DNA sequence analysis of scFv of sKDR}

\section{D1-7-binding clones}

DNA sequencing was performed with the Beckman Coulter (Fullerton, CA, USA) GenomeLab Methods Development kit protocol with primers 459 and 458 for forward and reverse reads. Sequencing reactions were run in a CEQ 8800 dye terminator cycle sequencing automated sequencing system (Beckman Coulter). The nucleic acid sequences were analyzed at the San Diego Supercomputer Center Biology Workbench web site [29] (http://workbench.sdsc.edu). The variable regions of each clone were determined by using the ImMunoGeneTics information system (IMGT [30]) (http://imgt.cines.fr/).

\subsection{ScFv production in bacteria, renaturation of expressed ScFv, folding and purification}

To produce the two recombinant antibodies, the scFv-containing pDUCK phagemid vector was transferred into E. coli HB2151. Cells carrying the scFvs were grown overnight at $30^{\circ} \mathrm{C}$ in $2 \times$ YT containing ampicillin $(100 \mu \mathrm{g} / \mathrm{mL})$. The preculture was inoculated into fresh $2 \times$ YT medium containing ampicillin $\left(100 \mu \mathrm{g} / \mathrm{mL}\right.$ ) and incubated at $37^{\circ} \mathrm{C}$ to $D_{600}$ (attenuance at $600 \mathrm{~nm}$ ) of 0.6 ; induction was performed for $4 \mathrm{H}$ at $30^{\circ} \mathrm{C}$ by adding $1 \mathrm{mM}$ (final concentration) isopropyl $\beta-\mathrm{D}-1-$ thiogalactopyranoside [31]. The cultures were harvested by centrifugation at 2,400g for $10 \mathrm{Min}$ and the supernatants were discarded. Periplasmic extraction of scFv was performed by resuspending the pellets in $5.3 \mathrm{~mL}$ TES buffer (0.2 M Tris-HCl pH 8.0, $0.5 \mathrm{mM}$ ethylenediaminetetraacetic acid EDTA, $0.5 \mathrm{M}$ sucrose) and incubating on ice for $5 \mathrm{Min}$. The cells were incubated on ice for an additional 20 Min after adding $6 \mathrm{~mL}$ of a one-third dilution of TES buffer. Cells were harvested by centrifugation at $23,700 \mathrm{~g}$ for $10 \mathrm{Min}$ at $4^{\circ} \mathrm{C}$. The supernatant was removed and the pellet was subjected to an inclusion body extraction protocol [32]. The pellet was dissolved in lysis buffer (50 mM Tris pH 8.0, $200 \mathrm{mM}$ $\mathrm{NaCl}, 1 \mathrm{mM}$ EDTA) containing $0.2 \mathrm{mg} / \mathrm{mL}$ lysozyme, then sonicated six times for $10 \mathrm{Sec}$ after $30 \mathrm{Min}$ incubation on ice and centrifuged at $17,400 \mathrm{~g}$ for $15 \mathrm{Min}$ at $4^{\circ} \mathrm{C}$. After the final sonication step, SDS was added to a final concentration of $1 \%$ in the sonication suspension and incubated at room temperature for $30 \mathrm{Min}$. The suspension was centrifuged for $30 \mathrm{Min}$ at $17,400 \mathrm{~g}$ and $4^{\circ} \mathrm{C}$. The pellet was resuspended in $12 \mathrm{~mL}$ lysis buffer and centrifuged for $20 \mathrm{Min}$ at $17,400 \mathrm{~g}$ and $4^{\circ} \mathrm{C}$. The pellet was resuspended in $50 \mathrm{mM}$ Tris buffer (pH 8.0) containing $6 \mathrm{M}$ urea and incubated on ice for 45 Min before a final 30 Min centrifugation $(17,400 \mathrm{~g})$. Finally, the pellet was resuspended in PBS. Supernatants were obtained after each centrifugation and analyzed by SDS-PAGE and western blot.

The final supernatants containing the purified scFvs of both clones (KDR1.3 and KDR2.6) were dialyzed against refolding buffer (20 mM NaHCO $3,150 \mathrm{mM} \mathrm{NaCl}, 2 \mathrm{mM}$ EDTA, pH 8.0) containing L-arginine for two nights at $4^{\circ} \mathrm{C}$ and against sonication buffer (20 mM Tris- $\mathrm{HCl}$ pH 8.0, $100 \mathrm{mM} \mathrm{NaCl}$ ) for two more nights. The scFvs were extracted from the dialyzed supernatants on a metal affinity column (BD Bioscience, San Jose, CA, USA). Eluted samples were dialyzed with PBS and then analyzed by SDS-PAGE and Western blot. The ScFv concentration was 
determined by the bicinchoninic acid method (Pierce Europe, Oud-Beijerlands, The Netherlands).

\subsection{Properties of scFvs binding to SKDR D1-7 ELISA}

Each well of an ELISA plate was coated with $500 \mathrm{ng}$ of target antigen at $4^{\circ} \mathrm{C}$ overnight. The next day, the wells were washed three times with $200 \mu \mathrm{L}$ TPBS (0.1\% Tween-20 in PBS) and then blocked with $200 \mu \mathrm{L}$ blocking buffer (PBS $+1 \%$ BSA) for $1 \mathrm{H}$ at room temperature. Wells were then washed with TPBS and $1 \mu \mathrm{g}$ anti-KDR recombinant antibodies were added and incubated at room temperature for $2 \mathrm{H}$. Wells were washed with TPBS and anti-Myc tag HRP-conjugated antibody conjugate (SigmaAldrich, Taufkirchen, Germany; 1:5,000) was added and incubated at room temperature for $1 \mathrm{H}$. A color reaction was acquired with ABTS substrate solution (Pharmacia Biotech; catalogue \#27-9402-01). After $1 \mathrm{H}$ incubation at room temperature, the absorbance $A_{405}$ was detected with an ELISA reader (Bio-Rad).

\subsection{SPR spectroscopy}

The SPR spectroscopy and SPR slides were obtained from Reichert Instruments (Reichert Technologies, Depew, NY, USA). The SPR chip surfaces were functionalized overnight with mercaptoundecanoic acid (Sigma) to form self-assembled monolayers (SAMs) of - $\mathrm{COOH}$-terminated thiols. The functionalized SPR surface was activated by injecting $\mathrm{N}$-hydroxysulfosuccinimide (NHS)/ethylene dichloride $(50 \mu \mathrm{M}$ NHS and ethanolamine, Sigma) in a flow cell.

SKDR D1-7 solution was passed across the activated SAM surface at a constant flow rate $(2 \mu \mathrm{L} / \mathrm{Min})$ at $25^{\circ} \mathrm{C}$. After immobilization of SKDR D1-7 on the surface, loosely bound and unbound receptors were removed by extensive washing of the chip surface with buffer solution. To block the amine-coupling end of SAMs, ethanolamine was passed across the sKDR D1-7 decorated SPR chip surface. Interaction of the recombinant antibodies with SKDR D1-7 was monitored by passing the antibodies over the chip surface at 1,2 , and $3 \mu \mathrm{M}$.

\subsection{Culture of HUVECS}

Human umbilical vein endothelial cells were isolated and cultured using a modification of the procedure described by Jaffe et al. [33]. Briefly, untraumatized umbilical cord segments were cannulated and flushed with Buffer $\mathrm{K}$ (10 mM Hepes $\mathrm{pH} 7.3,140 \mathrm{mM} \mathrm{NaCl}, 4 \mathrm{mM} \mathrm{KCl}$, and $11 \mathrm{mM}$ D-glucose). Cells were released from the vessel wall by incubating umbilical veins with $0.05 \%$ collagenase/dispase (Roche Molecular Biochemicals, Mannheim, Germany) at $37^{\circ} \mathrm{C}$ for $10 \mathrm{Min}$. The cells were flushed from the veins with $50 \mathrm{~mL}$ Medium 199 (M199) and after centrifugation $\left(200 \mathrm{~g}, 25^{\circ} \mathrm{C}, 5 \mathrm{Min}\right)$ the cell pellet was washed in M199. Cells were transferred to tissue culture plates coated with human plasma fibronectin $(40 \mu \mathrm{g} / \mathrm{mL})$ and maintained in endothelial cell growth medium (ECGM; M199 containing $20 \%$ fetal bovine serum FBS, $20 \mathrm{mM}$ Hepes $\mathrm{pH}$ 7.4 , penicillin $100 \mathrm{U} / \mathrm{mL}$, streptomycin $100 \mu \mathrm{g} / \mathrm{mL}$, and heparin $5 \mathrm{U} / \mathrm{mL}$ Liquemine; Roche) supplemented with crude endothelial growth factor [34]. All cell culture reagents were obtained from Biochrom (Biochrom KG, Berlin, Germany).

\subsection{HUVEC proliferation assay}

To test the VEGF blocking activity of the recombinant antibodies, HUVECs were plated onto 96-well tissue culture plates coated with $1 \%$ gelatin (Sigma) at a density of 5,000 cells/well in ECGM. After allowing the cells to attach, the medium was replaced with ECGM containing $2 \%$ FBS and cells were cultivated for $16 \mathrm{H}$. At this time, recombinant human $\mathrm{VEGF}_{165}\left(\mathrm{rhVEGF}_{165}\right)(5 \mathrm{ng} / \mathrm{mL}$; $\mathrm{NCl}$, Biological Resources Branch, Rockville, MD, USA) alone or together with filter-sterilized recombinant antibodies, KDR1.3, KDR2.6, or VEGF-neutralizing commercial antibody MAB293 (R\&D Systems, Minneapolis, MN, USA) were added to ECGM containing $2 \% \mathrm{FBS}$ and the cells were incubated for $48 \mathrm{H}$. In the last $18 \mathrm{H}$ of incubation, bromodeoxyuridine (BrdU) was added at a final concentration of $10 \mu \mathrm{M}$. At the end of the experiment, cells were washed and processed for BrdU labeling using the 5-Bromo-2'-deoxy-uridine Labeling and Detection Kit III (Roche Molecular Biochemicals).

\subsection{In vivo CAAs}

Inhibitory potentials of antibodies have been investigated with an in vivo rat CAA. Methodological principles of the experimental model have been previously described in detail [35]. In brief, human brain arteriovenous malformation (bAVM) tissue with high angiogenic potential [36],[37] was obtained, with informed consent, from a patient who underwent a AVM surgical resection at the Institute of Neurological Sciences, Marmara University (Istanbul, Turkey). The tissue was implanted into a micropocket created within the avascular rat cornea. Angiogenesis was stimulated in the avascular corneal matrix with the implantation of the bAVM tissue. The angiogenic potential of the tissue was estimated by counting new vessel formation.

Three rats for each group, that is, six corneas for each antibody (KDR1.3, KDR2.6, and negative control Lig $7 \mathrm{ScFv}$, specific to hepatitis $B$ virus surface antigen $\mathrm{HBsAg}$ ) were used. Antibodies $(200 \mu \mathrm{L}, 25 \mathrm{ng} / \mu \mathrm{L})$ were injected intravenously for 9 days at the same time of day. All groups were followed for 9 days and each cornea was photographed on days 3, 5, 7, and 9 under a microscope (Carl-Zeiss, Göttingen, Germany). The degree of angiogenesis was assessed by a blinded observer who counted the number of vessels. General linear mode univariate variation analysis was applied. For the post-hoc comparison, Tukey's honestly significant difference and Student-NewmanKeuls tests were used (SPSS 15.0, SPSS Inc., Chicago, IL, USA). The results were interpreted and compared as a function of time by using the cell line charts with error bars indicating one SEM.

\section{Results and discussion}

Vascular endothelial growth factor expression increases in different types of cancer such as glioblastoma, colorectal cancer, non-small cell lung cancer, and pancreatic cancer [38]. VEGF and VEGF receptors are, therefore, priority targets for suppression of pathologic angiogenesis. It is possible to inhibit VEGF function by inhibiting different steps in the signaling pathway triggered by VEGF binding to transmembrane tyrosine kinase receptors on endothelial cells. Such inhibitory molecules have been developed against VEGF and VEGF receptors. Today, studies focusing 


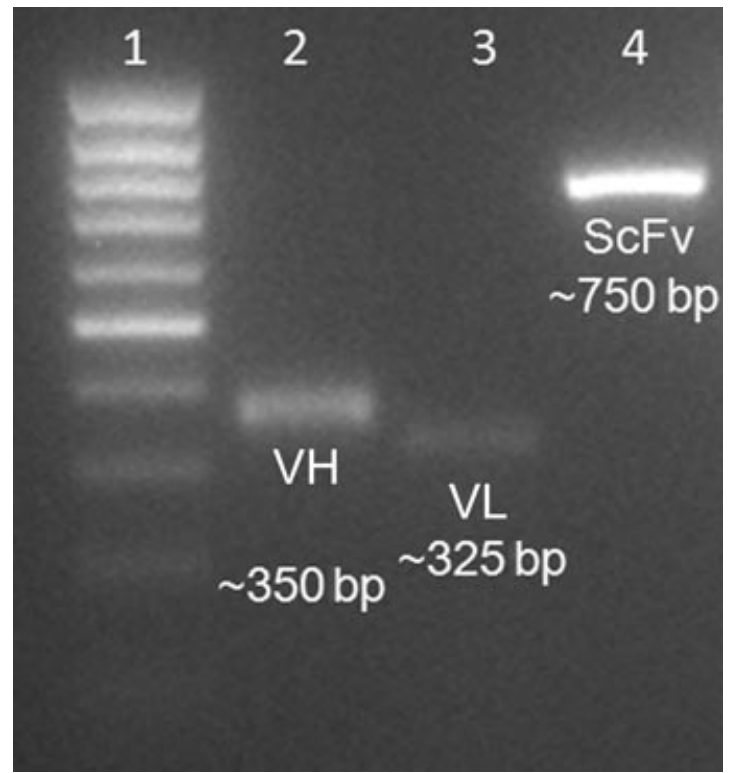

Fig. 1. Agarose gel image of variable heavy (VH) chain, light chain (VL), and the single-chain variable fragment (scFv) produced from the ligation of variable light and heavy chains with a linker coding for $\left(\mathrm{Gly}_{4} \mathrm{Ser}\right)_{3}$. on suppression of angiogenesis by targeting VEGF and its receptors have been intensified and many strategies have been developed to this end. Antibody structures in ScFv form were obtained following immunization of Balb/c mice with the extracellular domain of KDR fused to human placental alkaline phosphatase (KDR-AP) [39]. Employing phage display technology and using human antibody libraries, candidate antibody structures for antiangiogenic applications in the form of Fab and chimeric antibody have been developed [40]. Humanized monoclonal VEGF antibody bevacizumab [41] and antibody fragment ranibizumab [42] are examples of monoclonal antibody structures in antiangiogenic clinical applications.

RhuMab VEGF (Bevacizumab), a recombinant human monoclonal VEGF antibody with antiangiogenic and antitumor activity [43], and the monoclonal human antibody IMC-18F1 against VEGFR-1 [44] are the most important antiangiogenic agents developed so far. VEGF-Trap glioma-animal models with VEGFR1 and VEGFR2 structures hybridized to the human immunoglobulin $\mathrm{G} 1$ conserved region have been used to demonstrate successful reduction of tumors in the beginning and advanced stages [45]. Ranibizumab (48.0 kDa) is composed of the Fab (antigenbinding) section of anti-VEGF monoclonal antibody; smaller than the monoclonal antibody bevacizumab $(148 \mathrm{kDa})$ from which it is derived, ranibizumab is able to pass through the internal membrane after intravitreal application and inhibits all VEGF isoforms [46]. Promising results have been obtained in the use of ranibizumab in age-related macular degeneration [47]. Various studies have demonstrated that phage display technology can be effective for the identification of new antiangiogenic recombinant antibody structures [48],[49] or tumor-related biomarker proteins [50].
ELISA results

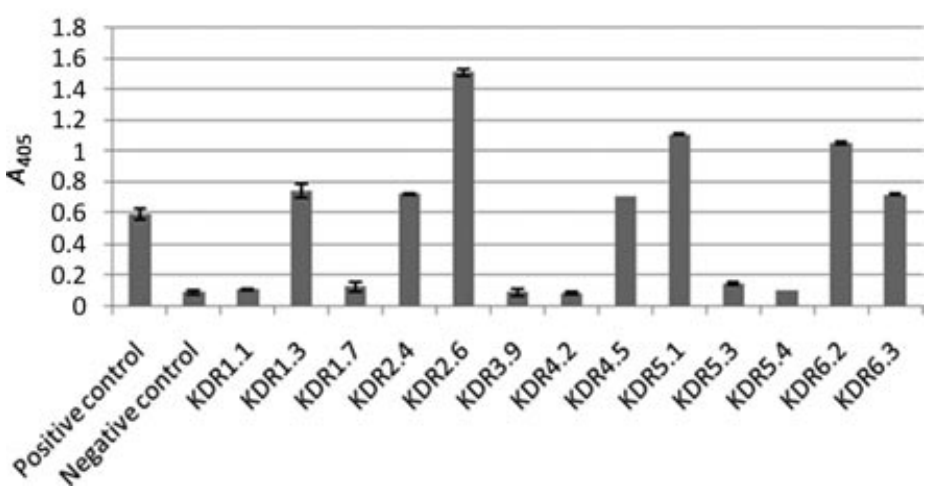

Fig. 2. Phage ELISA of randomly selected colonies obtained from the transformation of $E$. coli TG1 with the ligation product of anti-KDR scFv.
In this study, instead of using antibodies that are approximately $150 \mathrm{kDa}$ in size, we used phage display to obtain $33-\mathrm{kDa}$ recombinant scFv antibodies following selection in a recombinant antibody library developed after immunization of BALB/C J mice with recombinant SKDR D1-7.

\subsection{Library construction and biopanning for selection of SKDR D1-7-binding ScFv}

Each mouse was immunized with $15 \mu \mathrm{g}$ SKDR D1-7. Total RNA was extracted from spleen cells and cDNAs were generated by reverse transcription. Using these cDNAs as a template, $\mathrm{VH}$ (340 bp) and VL (325 bp) chain variable regions were PCR amplified (Fig. 1). scFv construction was carried out via two-stage PCR. VH and VL PCR products were assembled into scFv by PCR using a (Gly $\left.{ }_{4} \mathrm{Ser}\right)_{3}$ sequence as linker (Fig. 1). Approximately 750-bp assembled scFvs were digested with Notl and $S$ fil and ligated into the phagemid vector pDUCK, then transformed into $E$. coli $\mathrm{TG}_{1}$ for expression of phage antibody. The amber codon, positioned between the myc tag and protein III, enables the construct to make scFv in surface-displaying format when transformed into a suppressor host (such as E. Coli TGI cells) and in soluble form when transformed into a nonsupressor host (such as E. Coli HB2151 cells). Enrichment of SKDR D1-7 binding phages was observed following the third biopanning step, whereas no increase was observed in the binding phages after the second round. The SKDR D1-7 binding clones were selected by phage ELISA by coating with $500 \mathrm{ng}$ of SKDR D1-7 and adding $10^{11}$ phages per well (Fig. 2). Eighty clones were randomly picked after the second round of biopanning and screened for binding to SKDR D1-7; 11 clones (14\%) bound to sKDR D1-7. The next day, the presence of scFv gene in 45 bacterial colonies was verified by colony PCR as 11 SKDR D1-7 binding clones and 34 randomly picked sKDR D1-7 nonbinders. The diversity of the selected scFv clones was analyzed by BstNI enzyme fingerprinting. 


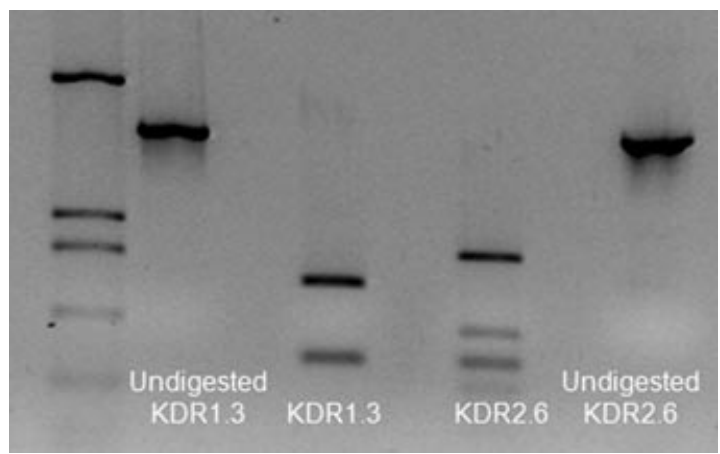

Fig. 3. BstNI digestion profile of KDR1.3 and KDR2.6 scFv clones.

\subsection{Sequence analysis}

DNA BstNI fingerprinting of 11 SKDR D1-7 binding clones indicated the presence of two different digestion patterns, whereas 34 randomly picked sKDR D1-7 nonbinders yielded four different patterns. Two clones, called KDR1.3 and KDR2.6 scFvs, were selected for further analysis (Fig. 3). DNA sequences belonging to KDR1.3 and KDR2.6 clones were compared with CLUSTALW-Multiple Sequence Alignment software from the San Diego Supercomputer Center Biology Workbench web site (http://workbench.sdsc.edu) and sequence differences confirmed the BstNI enzyme digestion results. The DNA sequences including the complementarity-determining regions of KDR1.3 and KDR2.6 scFvs are given in Figs. 4 and 5. KDR1.3 and KDR2.6 scFvs are 747 and 762 bp long. According to V-QUEST [51] from the IMGT web site (http://www.imgt.org), the KDR1.3 scFv heavy chain belongs to the $\mathrm{VH}_{3}$ family, whereas KDR2.6 scFv heavy chain belongs to the $\mathrm{VH}_{1}$ family, both with light chains belonging to the kappa VL4 family.

\subsection{SKDR D1-7 binding of purified SCFv}

KDR1.3, KDR2.6, and the HBsAg-specific Lig7 scFvs were expressed using a nonsuppressor host $E$. coli HB2151 for expression of soluble scFv in shake flasks. The scFvs were extracted from cells by a treatment with lysis buffer and sonications. The soluble scFvs were refolded by dialysis and purified with metal affinity resin. After purification steps, the amounts of purified scFvs were $120 \pm 35 \mathrm{ng} / \mu \mathrm{L}$ (KDR1.3 ScFv) and $105 \pm 20 \mathrm{ng} / \mu \mathrm{L}$ (KDR2.6 scFv). The $\sim 33 \mathrm{kDa}$ molecular weight scFvs were determined by SDS-PAGE and western blot analysis (Fig. 6). The binding ability of both scFvs to sKDR was detected by ELISA with a mouse anti-human c-myc tag antibody (DakoCytomation) as well as HRP-labeled polyclonal rabbit anti-mouse antibody (DakoCytomation) (Fig. 7).

KDR1.3 and KDR2.6 scFvs showed a specific binding signal of 0.250 and 0.512 at absorbance $A_{405}$ to SKDR D1-7 but not to BSA and HBsAg. Lig7 scFv used as control bound specifically (0.605 at $A_{405}$ ) to its antigen (HBsAg) but not to sKDR D1-7.

Solubly expressed KDR1.3 and KDR2.6 scFvs retained their sKDR D1-7 binding abilities so that they could be used for cell culture experiments. The sKDR D1-7 binding activities of the phage display-selected KDR1.3 and KDR2.6 scFvs were also investigated with SPR spectroscopy. The change in refractive index is an indication of ligand binding to the receptor molecule that is immobilized on the chip surface [52]. The binding sensograms are demonstrated in Fig. 8.

The binding experiments yielded the real-time binding of KDR 1.3 and KDR 2.6 to SKDR D1-7 immobilized on SPR chip surface. Another scFv molecule, which specifically binds to HBsAg, Lig 7, was included in the selectivity test. As shown in Fig. 8, KDR1.3 and KDR2.6 interacts with SKDR D1-7 but the nonspecific lig7 does not show significant binding to SKDR D1-7.

\subsection{Recombinant antibodies KDR1.3 and KDR2.6 specifically inhibit HUVEC proliferation}

To test whether KDR1.3 and KDR2.6 scFvs inhibit VEGF signaling and endothelial cell proliferation, we performed cell proliferation experiments with recombinant antibody-treated HUVEC cultures. Inhibition of HUVEC proliferation is an in vitro assay in which the effect of the antibody on VEGF-VEGFR interaction is measured indirectly through cell proliferation and is affected by the antibody concentration and affinity. Antibody 293, a commercially available antibody that has been shown to block endothelial cell proliferation in vitro and VEGF-induced angiogenesis in vivo, was used as a positive control. As shown in Fig. 9, KDR1.3 and KDR2.6 scFvs significantly suppressed the mitogenic response of HUVEC to rhVEGF $_{165}$ in a dose-dependent manner. At $1 \mu \mathrm{g} / \mathrm{mL}$, antibody 293, KDR1.3 scFv, and KDR2.6 SCFv reduced VEGF-dependent proliferation by $84 \pm 20.1 \%$, $60 \pm 23.7 \%$, and $40 \pm 17.4 \%$. Inhibition of proliferation by both antibodies was significant; however, it was lower than that of the commercial antibody, which has been reported by the manufacturer to be $80 \%$ with $10 \mathrm{ng} / \mathrm{mL}$ rhVEGF. KDR1.3 scFv yielded consistently higher inhibition at the tested concentration, but this was statistically insignificant. The inhibition rates were mean values obtained from four experiments and their calculated standard deviations were high, resulting in statistically insignificant differences between the two antibodies. Four different HUVEC cell proliferation experiments performed with antibodies obtained from four different preparations, each with slightly different antibody activities, have contributed to the variation of cell inhibition effects.

Overall, the inhibition of cell proliferation by KDR1.3 and KDR2.6 scFvs suggests that the identified recombinant antibodies bind VEGF interfering with receptor interactions on HUVECs. This inhibition is sufficiently potent to inhibit VEGF signaling and cell proliferation, which is a downstream event.

The described method has been applied in other studies. Zhu et al. [53] produced a scFv ( $\left.\mathrm{p}_{1} \mathrm{C}_{11}\right)$ with $2.1 \mathrm{nM}$ affinity for KDR by immunizing mice with KDR-AP. They reported $48 \%$ inhibition of HUVEC proliferation with $1 \mu \mathrm{g} / \mathrm{mL}$ KDR. Furthermore, a rat monoclonal antibody developed against Flk1 inhibited $\mathrm{G}_{55}$ cell proliferation by $25 \%$ [54]. A monoclonal antibody (YcomB3) developed against KDR immunoglobulin domain III inhibited HUVEC proliferation by $50 \%$ at $0.5 \mathrm{mg} / \mathrm{L}$ and, it was proposed as a candidate for antiangiogenic applications [55]. 
$\begin{array}{llllllllllllllllllllllll}I & L & G & E & V & I & M & K & Y & I & I & P & T & A & A & A & G & I & I & I & I & A & A\end{array}$ ctt tta gga gaa gtc ata atg aaa tac cta ttg cct acg gca gcc get gga ttg tta tta ctc gcg gcc

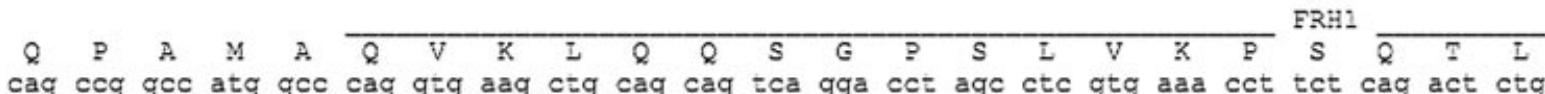
CDRH1

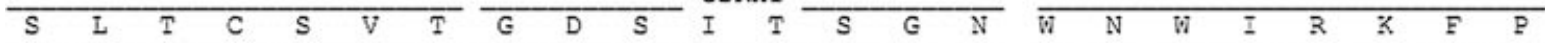
tcc ctc acc tgt tct gtc act ggc gac tcc atc acc agt ggt aac tgg aac tgg atc cgg aaa ttc cca

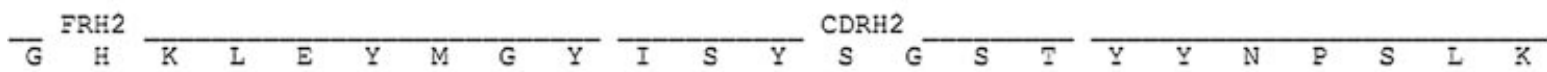
ggg cat aaa ctt gag tac atg ggg tac ata agc tac agt ggt agc act tat tat aat cca tct ctc aaa FRH3

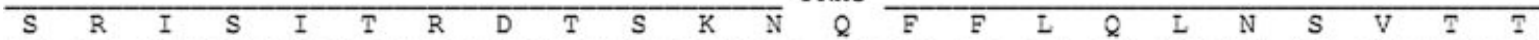

agt cga atc tct atc act cga gac aca tcc aag aac cag ttc ttc ctg cag ttg aat tct gtg act act CDRH3

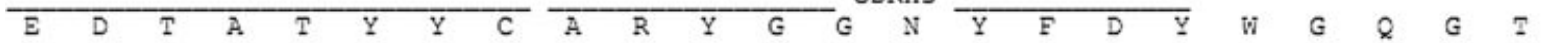
gag gac aca gcc aca Tat tac tgt gca aga tat ggt ggt aac tac ttt gac tac tgg ggc caa ggg acc

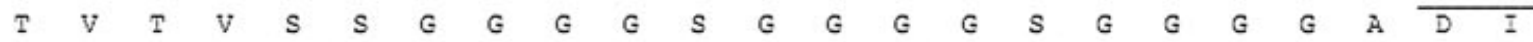
acg gtc acc gtc tcc tca ggt gga gge ggt tca gge gga ggt gge tct gge ggt gge gga gcg gac atc \begin{tabular}{llllllllllllllllllllllll}
\hline E & L & T & $Q$ & $S$ & P & A & I & $M$ & $S$ & A & $S$ & P & G & E & K & V & T & M & T & $C$ & $S$ & A
\end{tabular} gag ctc act cag tct cca gca atc atg tct gca tct cca ggg gag aag gtc acc atg Acc tgc agt gcc

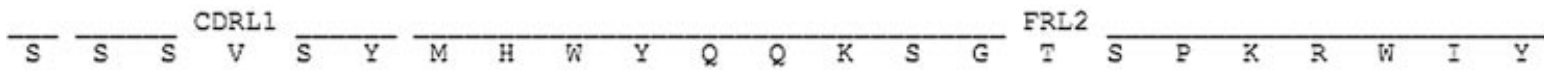
agc tca agt gta agt tac atg cac tgg tac cag cag aag tca ggc acc tcc ccc aa aga tgg att tat

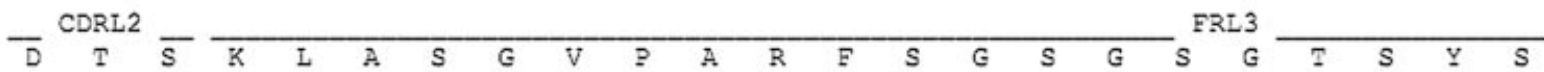
gac aca tcc aa ctg get tct gga gtc cct gct cgc ttc agt ggc agt ggg tct ggg acc tct tac tct

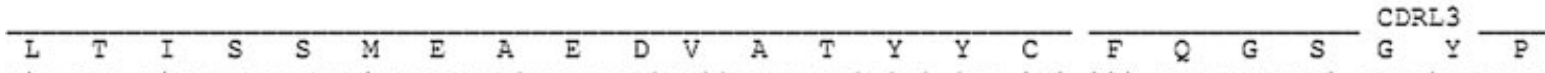
ctc aca atc agc agc atg gag gct gaa gat gtt gcc act tat tac tgt ttt cag ggg agt ggg tac cca

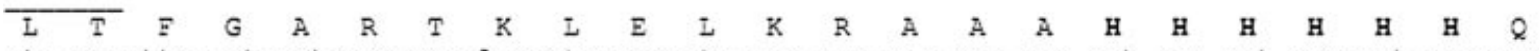
ctc acg ttc ggt gct agg acc Aag ctg gag ctg aaa cgg gcg gcc gca cat cac cat cac cat cac cag

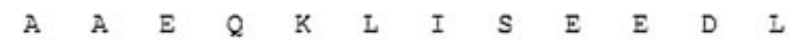

gcc gca gaa caa aaa ctc atc tca gaa gag gat ctg

Fig. 4. Protein and DNA sequences of KDR1.3 ScFv and the placement of complementarity-determining regions and framework region (FR) predicted by V-QUEST from the IMGT web site by IMGT [51] (http://www.imgt.org). H, heavy chain; L, light chain.

\subsection{In vivo CAAs}

Both KDR1.3 and KDR2.6 scFvs successively suppressed the AVM-induced neovascularization in avascular cornea $(p<0.05)$. However, animals in the KDR2.6 group died by day 9 of the assay, without any observable seizures or symptoms. Representative cornea images and temporal analysis of vessels for each group are shown in Figs. 10 and 11.

The in vivo CAA demonstrated that these recombinant molecules strongly inhibited tissue-induced neovascularization in rat cornea. Although the number of vessels formed in the Lig 7 control group was $\sim 18$ vessels/cornea at day 7 , less than $\sim 2$ vessels/cornea was observed for KDR1.3 and KDR2.6 groups. However, the death of KDR2.6-injected animals raises concerns regarding the use of these antibodies in clinical therapy. Avoiding serious toxic effects is critical in oncology because most regimens contain potent cytotoxic drugs; nevertheless, it has been difficult to identify biomarkers for toxicity, primarily because of the low incidence of serious adverse events such as hemorrhage and perforations. The humanized monoclonal antibody bevacizumab is a well-tolerated VEGF inhibitor but carries the risk of a variety of adverse effects such as hypertension and pulmonary hemorrhage [56],[57]. Pharmacogenetic variability has been linked to bevacizumab toxicity [58]. To uncover the physiopathological causes of the deaths in our experimental animals, we plan to further perform animal experiments with KDR2.6 scFv. 


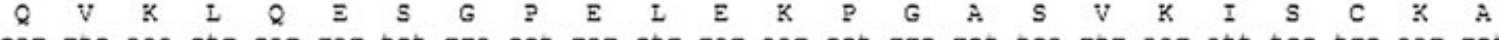
cag gtc aaa ctg cag gag tct gga cct gag ctg gag aag cet ggc gct tca gtg aag att tcc tgc aag gct CDRH 1 ₹RH2

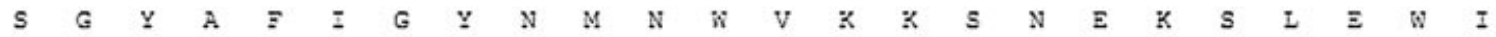
tce ggt tac gca ttc att ggc tac aac atg aac tgg gtg aag aag agc aat gaa aag agc ctt gag tgg att CDR: 2

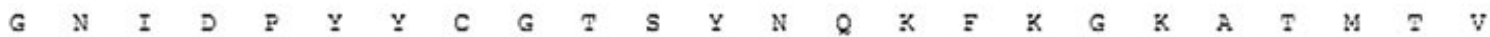
gga aat att gat cet tac tat tgt ggg act agc tac aac cag aag ttc aag gge aag gce aca atg act gta
\end{abstract} FRH3

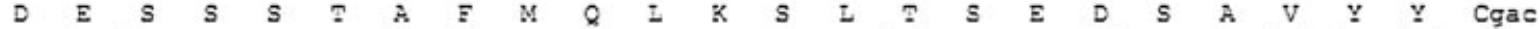
gaa tce tcc agc aca gce ttc atg cag cte aag agc ctg aca tet gag gac tct gca gtc tat tac tgt $\operatorname{CDR}: 3$

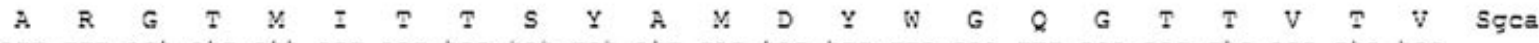
agg ggg act atg att acg acg tcc tat gct atg gac tac tgg ggc caa ggg acc acg gtc acc gtc tcc

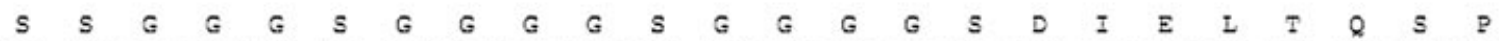
tca agt gga ggc ggt tca gge gga ggt gge tet ggt ggt gge gga teg gac ate gag cte act cag tet cca

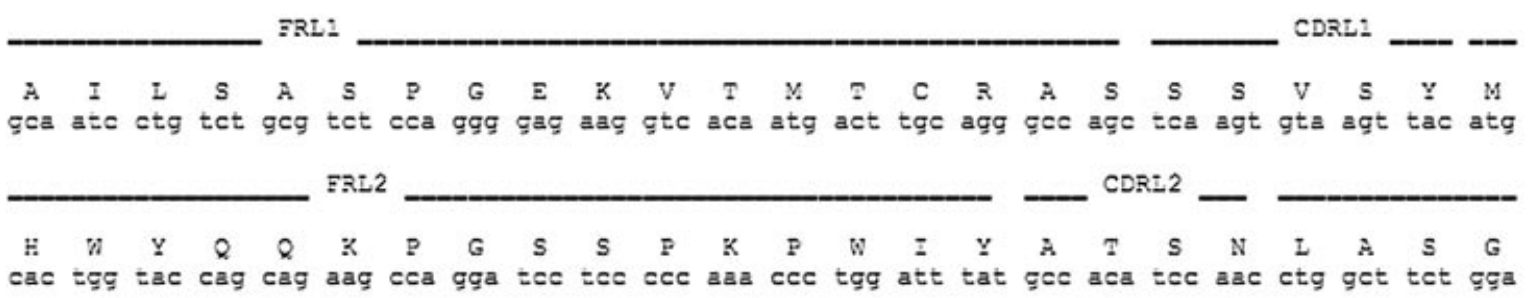
FRL3

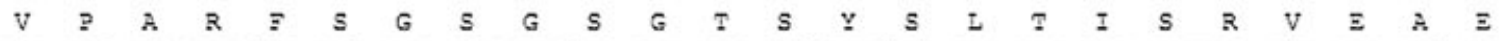
gtc ect gct cgc ttc agt ggc agt ggg sct ggg acc tct tac tct ctc aca atc agc aga gtg gag gct gaa CDRL3

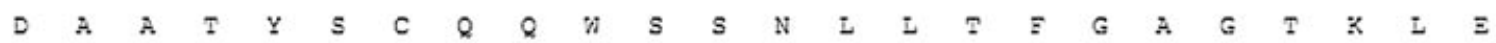

gat gct gcc act tat tcc tgc cag cag ggg agt agt aac ctg etc acg tec ggt gct ggg acc aag ctg gaa

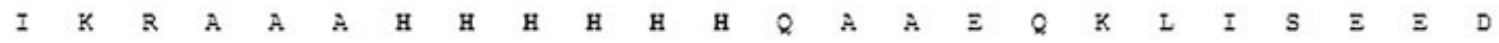

ata aad cgg gcg gcc gca cat cac cat cac cat cac cag gce gca gaa caa aa etc atc tca gaa gag gat

I N G A A

$\operatorname{ctg} a a t g g g$ gcc gca

Fig. 5. Protein and DNA sequences of KDR2.6 ScFv and the placement of complementarity-determining regions and framework region (FR) predicted by V-QUEST from the IMGT web site [51] (http://www.imgt.org). H, heavy chain; L, light chain.

\section{Conclusion}

In this study, we generated and analyzed two single-chain antibodies (KDR1.3 and KDR2.6) specific for the human recombinant soluble VEGFR2/KDR domains 1-7, also known as the KDR receptor. The antibodies bind to the extracellular domain and block the VEGF-receptor interaction necessary for ligandinduced proliferation. The molecular characteristics, specificity, and neutralizing capacities of the these single-chain antibodies were demonstrated by BstNI fingerprinting; the amino acid sequence of the VH and VL domains of the scFv fragments; western blot analysis of soluble scFvs; ELISA analysis with soluble 


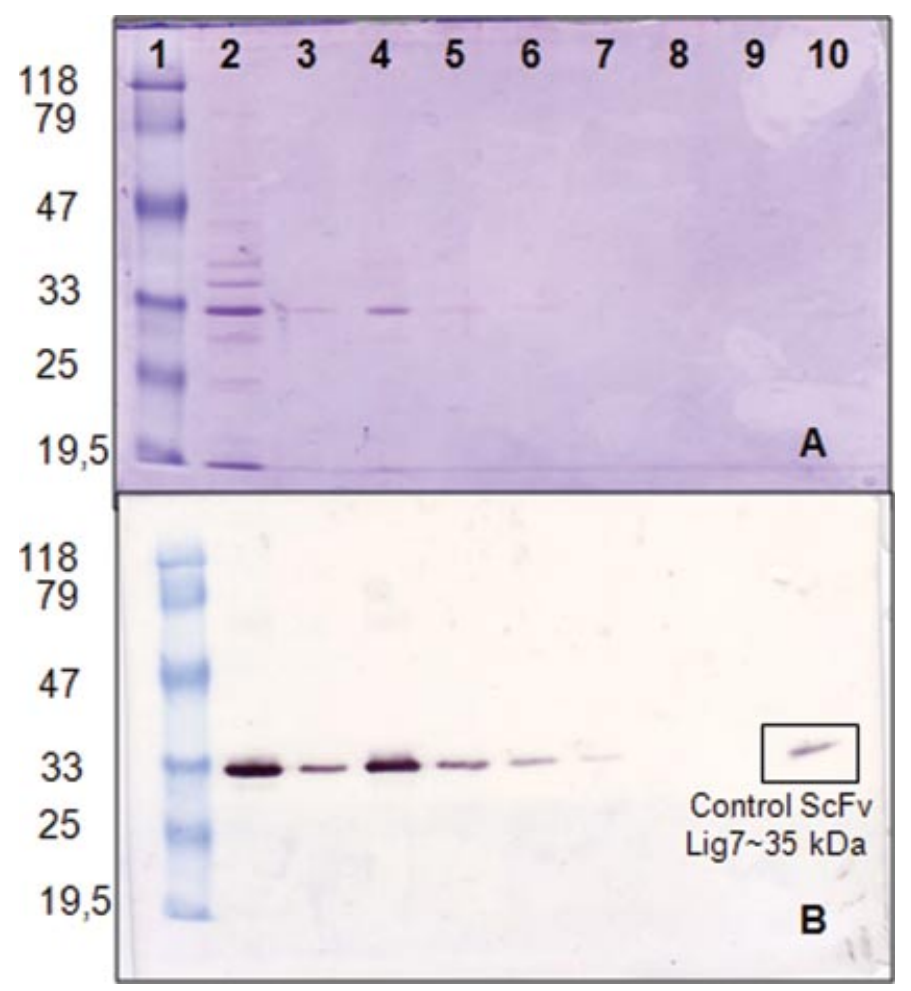

Fig. 6. SDS-PAGE (A) and western blot (B) analysis of metal affinity column-purified KDR2.6 scFv. Lane 1, molecular weight marker; lanes 2-9 indicate elution fractions; lane 10, Lig7 scFv control.

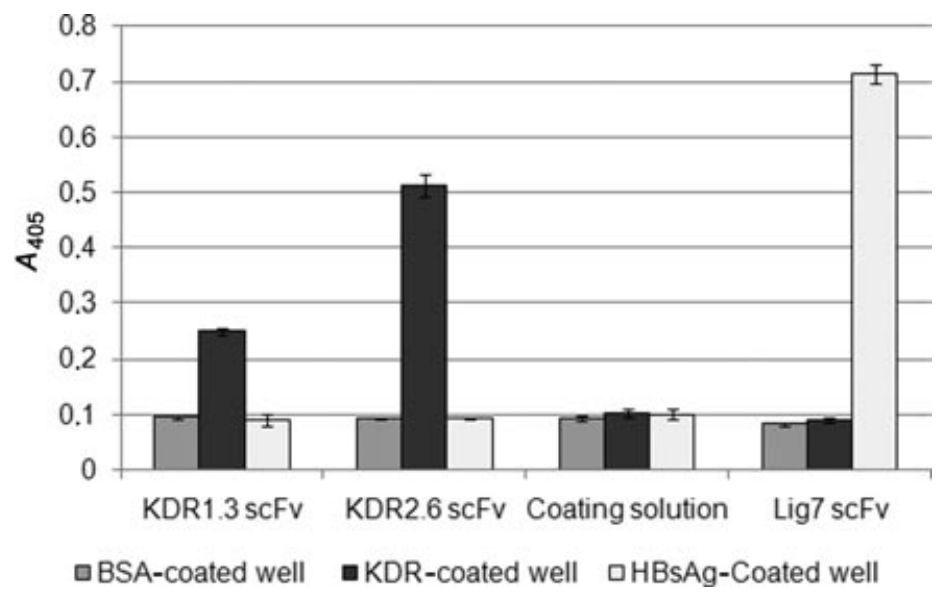

Fig. 7. ELISA of metal-affinity-purified KDR1.3, KDR2.6, and Lig7 (HBsAg specific) scFvs. Five hundred nanograms of antigens was immobilized. Binding of scFvs to the antigens was evaluated by the addition of $1 \mu \mathrm{g}$ of scFvs, followed by anti-Myc tag HPR-conjugated antibody. The $A_{405}$ demonstrates specific binding of KDR1.3 and KDR2.6 scFvs to SKDR D1-7 and no binding to BSA or HBsAg. No binding to SKDR D1-7 was visualized for Lig7 ScFv but it was specifically binding to its antigen, HBsAg.

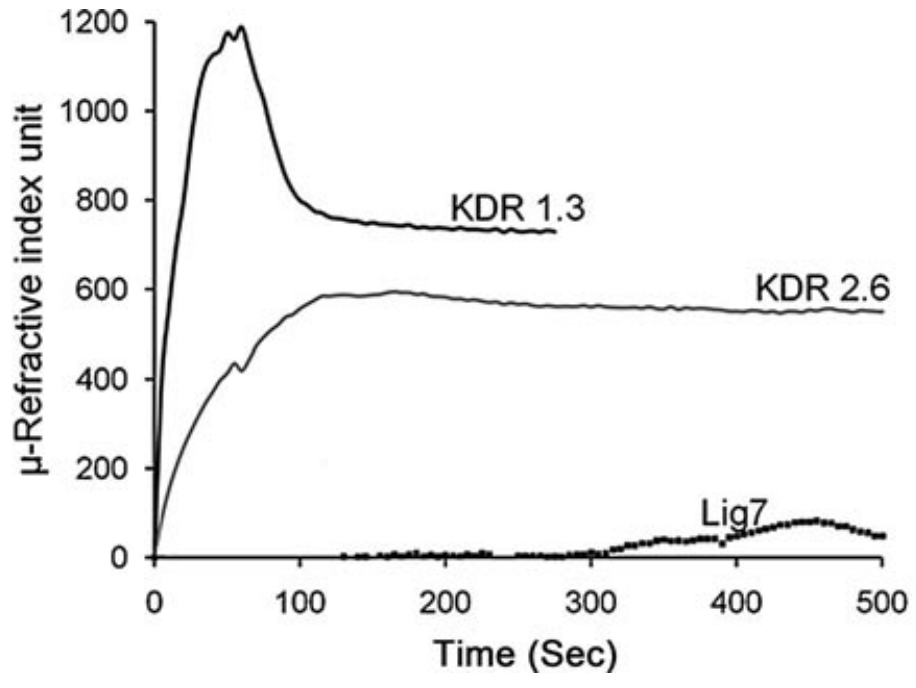

Fig. 8. Comparison of binding signals of selected ligand molecules, KDR1.3 and KDR2.6, with a nonspecific ligand molecule, Lig7. The refractive index change corresponds to the amount of binding.

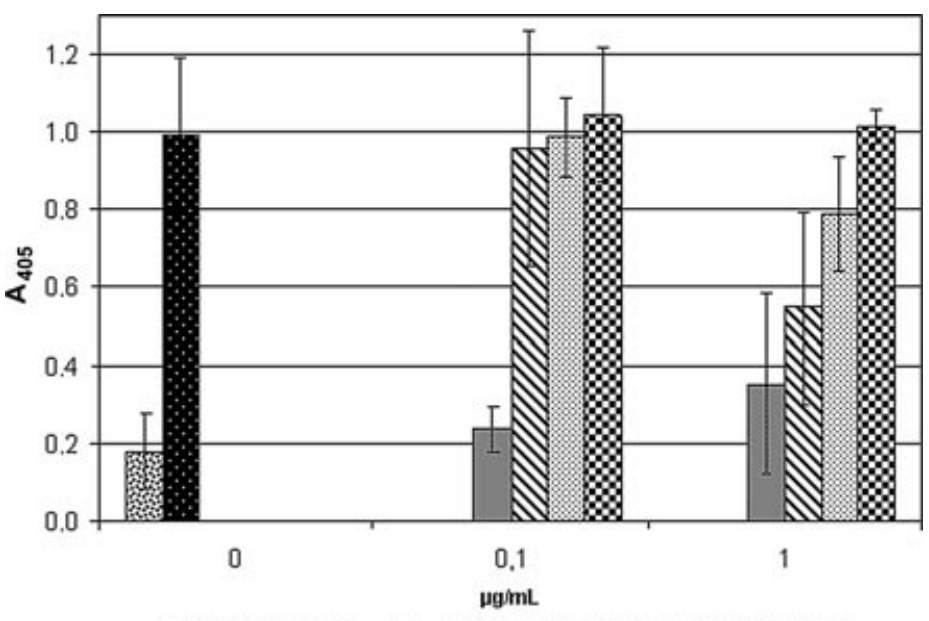

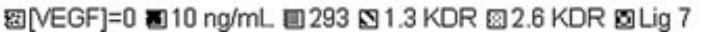

Fig. 9. Recombinant antibodies KDR1.3 and KDR2.6 inhibit VEGF-induced HUVEC proliferation in a dose-dependent manner. HUVECs were grown in M199 containing $2 \%$ FBS without rhVEGF ${ }_{165}$ (small dotted bars), supplemented with $5 \mathrm{ng} / \mathrm{mL} \mathrm{rhVEGF}_{165}$ alone (black bars), $5 \mathrm{ng} / \mathrm{mL} \mathrm{rhVEGF}_{165}$ preincubated with $1 \mu \mathrm{g} / \mathrm{mL}$ VEGF-neutralizing antibody (MAB293) (gray bars), or various concentrations of KDR1.3 scFv (diagonal striped bars), KDR2.6 scFv (light dotted bars), and Lig $7 \mathrm{ScFv}$ (large dotted bars). HUVECs were used at passage 5. Cell proliferation was quantified in terms of BrdU incorporation (measured and indicated as $\mathrm{OD}_{450}$ ). The data points were obtained in triplicate; representative results from one of four independent experiments are shown. 


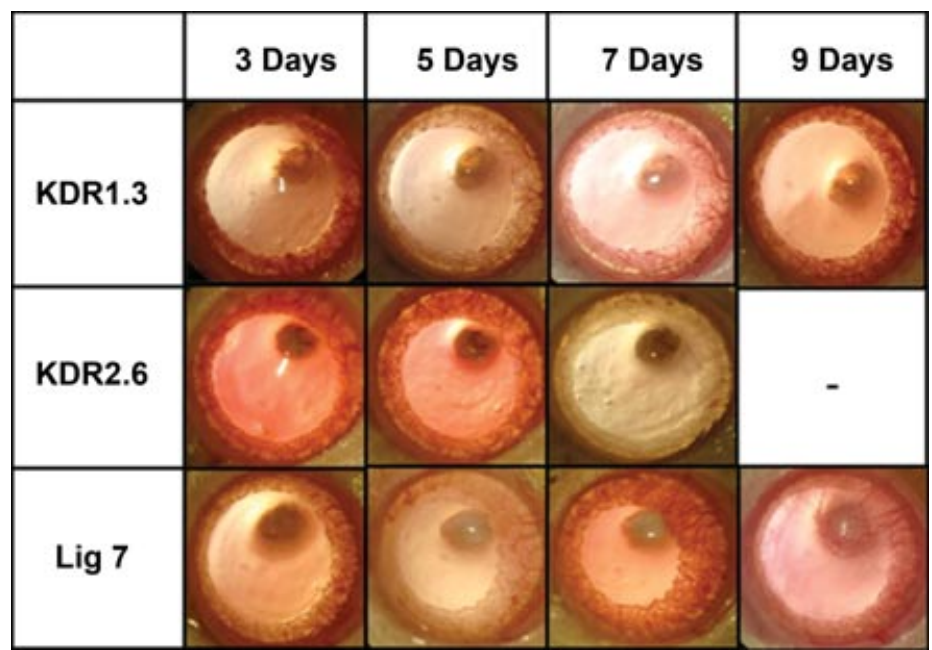

Fig. 10. Representative cornea images from CAA for KDR1.3, KDR2.6, and Lig7 ScFvs. Cornea images were taken under microscope (Carl-Zeiss) after the treatment of CAA with KDR1.3, KDR2.6, and Lig7 scFvs at days 3, 5, 7, and 9 for the calculations of the degree of angiogenesis.

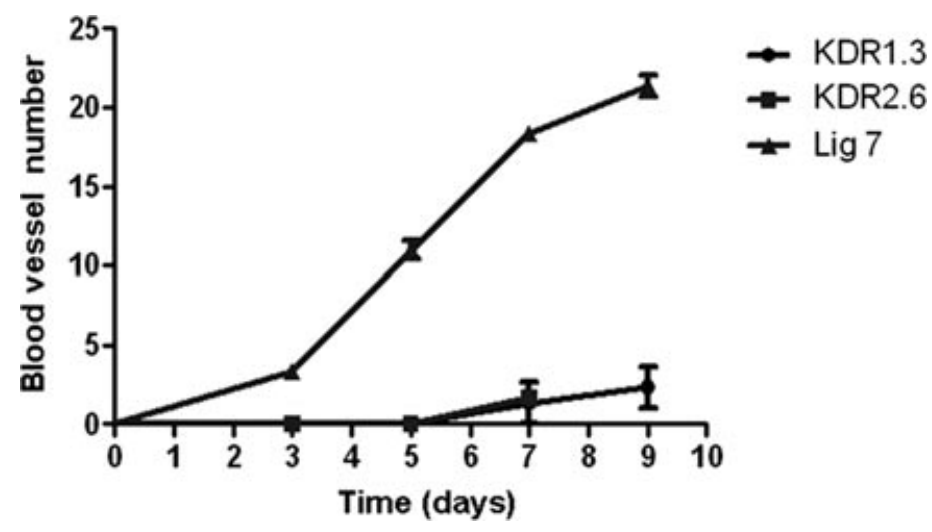

Fig. 11. Temporal analysis of vessels formed in CAA for KDR1.3, KDR2.6, and Lig 7 scFvs. The degree of angiogenesis was assessed by a blinded observer who counted the number of vessels. General linear mode univariate variation analysis was applied. For the post-hoc comparison, Tukey's honestly significant difference and Student-Newman-Keuls tests were used (SPSS 15.0). The results were interpreted and compared as a function of time by using the cell line charts with error bars indicating one SEM.

antigen; and binding of scFv fragments to HUVECs. Results also showed that KDR1.3 and KDR2.6 scFvs differ from each other, have specific binding to KDR, and both single-chain antibodies (clones 1.3 and 2.6) inhibited HUVEC proliferation in vitro up to $40 \%$ and $60 \%$, whereas VEGF neutralizing antibody (MAB293) inhibited between $60 \%$ and $80 \%$. In vivo CAA analyses verified these findings. The identified and characterized new recombinant antibodies, which block VEGF binding to KDR, have po- tential clinical application in the treatment of cancer and other diseases involving pathological angiogenesis.

\section{Acknowledgements}

This work was partially supported by a grant from TUBITAK Health Science Research Group projects (SBAG-MAM-1, $102 \mathrm{~S} 005$ and 102S834). We thank the National Cancer Institute, Biological Resources Branch (Rockville, MD, USA) for the generous gift of rhVEGF $F_{165}$.

\section{References}

[1] Folkman, J. (1995) Nat. Med. 1, 27-31.

[2] Carmeliet, P. (2003) Nat. Med. 9, 653-66o.

[3] Neufeld, G., Cohen, T., Gengrinovitch, S., and Poltorak, Z. (1999) FASEB J. 13, 9-22.

[4] Ferrara, N. (2009) Arterioscler. Thromb. Vasc. Biol. 29, 789-791.

[5] Whitaker, G. B., Limberg, B. J., and Rosenbaum, J. S. (2001) J. Biol. Chem. 276, 25520-25531.

[6] Leung, D. W., Cachianes, G., Kuang, W. J., Goeddel, D. V., and Ferrara, N. (1989) Science 246, 1306-1309.

[7] Soker, S., Miao, H. Q., Nomi, M., Takashima, S., and Klagsbrun, M. (2002) J. Cell. Biochem. 85, 357-368.

[8] Ferrara, N., Gerber, H. P., and LeCouter, J. (2003) Nat. Med. 9, 669-676.

[9] Asahara, T., Murohara, T., Sullivan, A., Silver, M., van der Zee, R., Li, T., Witzenbichler, B., Schatteman, G., and Isner, J. M. (1997) Science 275, 964967.

[10] Ziegler, B. L., Valtieri, M., Porada, G. A., De Maria, R., Müller, R., Masella, B., Gabbianelli, M., Casella, I., Pelosi, E., Bock, T., Zanjani, E. D., and Peschle, C. (1999) Science 285, 1553-1558.

[11] Peichev, M., Naiyer, A. J., Pereira, D., Zhu, Z., Lane, W. J., Williams, M., Oz, M. C., Hicklin, D. J., Witte, L., Moore, M. A., and Rafii, S. (2000) Blood 95 952-958.

[12] Lu, D., Kussie, P., Pytowski, B., Persaud, K., Bohlen, P., Witte, L., and Zhu, Z. (2000) J. Biol. Chem. 275, 14321-14330.

[13] Folkman, J. (1971) N. Engl. J. Med. 285, 1182-1186.

[14] Kim, K. J., Li, B., Winer, J., Armanini, M., Gillett, N., Phillips, H. S., and Ferrara, N. (1993) Nature 362, 841-844.

[15] Hicklin, D. J., Witte, L., Zhu, Z., Liao, F., Wu, Y., Li, Y., and Bohlen, P. (2001) Drug Discov. Today 6, 517-528.

[16] Millauer, B., Shawver, L. K., Plate, K. H., Risau, W., and Ullrich, A. (1994) Nature 367, 576-579.

[17] Yu, Y., Lee, P., Ke, Y., Zhang, Y., Yu, Q., Jonathan Lee, J., Li, M., Song, J., Chen, J., Dai, J., Do Couto, F. J. R., An, Z., Zhu, W., and Yu, G. L. (2010) PLoS One 5, 1-12.

[18] Mordenti, J., Thomsen, K., Licko, V., Chen, H., Meng, Y. G., and Ferrara, N. (1999) Toxicol. Pathol. 27, 14-21.

[19] Yeung, Y. A., Wu, X., Reyes II, A. E., Vernes, J. M., Lien, S., Lowe, J., Maia, M., Forrest, W. F., Meng, Y. G., Damico, L. A., Ferrara, N., and Lowman, H. B. (2010) Cancer Res. 70, 3269-3277.

[20] Jain, R. K., Duda, D. G., Clark, J. W., and Loeffler, J. S. (2006) Nat. Clin. Pract. Oncol. 3, 24-40.

[21] Sharkey, R. M. and Goldenberg, D. M. (2006) Cancer Invest. 24, 82-97.

[22] Carmen, S. and Jermutus, L. (2002) Brief. Funct. Genomic. Proteomic. 1 , 189-203.

[23] Yokota, T., Milenic, D. E., Whitlow, M., and Schlom, J. (1992) Cancer Res. 52, 3402-3408.

[24] Batra, S. K., Jain, M., Wittel, U. A., Chauhan, S. C., and Colcher, D. (2002) Curr. Opin. Biotechnol. 13, 603-608.

[25] Lien, S. and Lowman, H. B. (2008) In Therapeutic Antibodies (Chernajovsky, Y., Nissim, A., eds.), pp. 131-150, Springer-Verlag, Berlin, Heidelberg.

[26] Sambrook, J., Fritsch, E. F., and Maniatis, T. (1989) Molecular Cloning: A Laboratory Manual. Cold Spring Harbor, NY: Cold Spring Harbor Laboratory Press.

[27] Smith, G. P. and Scott, J. K. (1993) Methods Enzymol. 217, 228-257. 
[28] Gussow, D. and Clackson, T. (1989) Nucl. Acids Res. 17, 4000.

[29] Subramaniam, S. (1998) Proteins 32, 1-2.

[30] Lefranc, M.-P., Giudicelli, V., Ginestoux, C., Jabado-Michaloud, J., Folch, G., Bellahcene, F., Wu, Y., Gemrot, E., Brochet, X., Lane, J., Regnier, L., Ehrenmann, F., Lefranc, G., and Duroux, P. (2009) Nucl. Acids Res. 37, 1006-1012.

[31] Sánchez, L., Ayala, M., Freyre, F., Pedroso, I., Bell, H., Falcón, V., and Gavilondo, J. V. (1999) J. Biotechnol. 72, 13-20.

[32] Das, D., Kriangkum, J., Nagata, L. P., Fulton, R. E., and Suresh, M. R. (2004) J. Virol. Methods 117, 169-177.

[33] Jaffe, E. A., Nachman, R. L., Becker, C. G., and Minick, C. R. (1973) J. Clin. Invest. 52, 2745-2756.

[34] Maciag, T., Cerundolo, J., Ilsley, S., Kelley, P. R., and Forand, R. (1979) Proc. Natl. Acad. Sci. U. S.A. 76, 5674-5678.

[35] Konya, D., Yildirim, O., Kurtkaya, O., Kiliç, K., Black, P. M., Pamir, M. N., and Kiliç, T. (2005) Neurosurgery 56, 1339-1345.

[36] Kiliç, K., Konya, D., Kurtkaya, O., Sav, A., Pamir, M. N., and Kiliç, T. (2007) J. Neurosurg. 106, 463-469.

[37] Akakin, A., Ozkan, A., Emel, A., Demet Yalcinkaya, K., Deniz, K., M. Necmettin, P., and Turker, K. (2010) Neurosurgery 66, 121-129.

[38] Ranieri, G., Patruno, R., Ruggieri, E., Montemurro, S., Valerio, P., and Ribatti, D. (2006) Curr. Med. Chem. 13, 1845-1857.

[39] Zhu, Z., Yin, Z., and Wu, M. (2000) Zhonghua Bing Li Xue Za Zhi 29, 300-302.

[40] Zhu, Z., Xing, S., Lin, C., Zhang, X., Fu, M., Liang, X., Zeng, F., Lu, G., and Wu, M. (2003) Chin. Med. J. (Engl.) 116, 1860-1863.

[41] Hurwitz, H., Fehrenbacher, L., Novotny, W., Cartwright, T., Hainsworth, J., Heim, W., Berlin, J., Baron, A., Griffing, S., Holmgren, E., Ferrara, N., Fyfe, G., Rogers, B., Ross, R., and Kabbinavar, F. (2004) N. Engl. J. Med. 350, 2335-2342.

[42] Kim, I. K., Husain, D., Michaud, N., Connolly, E., Lane, A. M., Durrani, K., Hafezi-Moghadam, A., Gragoudas, E. S., O'Neill, C. A., Beyer, J. C., and Miller, J. W. (2006) Invest. Ophthalmol. Vis. Sci. 47, 357-363.

[43] Monk, B. J., Choi, D. C., Pugmire, G., and Burger, R. A. (2005) Gynecol. Oncol. 96, 902-905.

[44] Wu, Y., Zhong, Z., Huber, J., Bassi, R., Finnerty, B., Corcoran, E., Li, H., Navarro, E., Balderes, P., Jimenez, X., Koo, H., Mangalampalli, V. R., Ludwig,
D. L., Tonra, J. R., and Hicklin, D. J. (2006) Clin. Cancer Res. 12, 65736584 .

[45] Gomez-Manzano, C., Holash, J., Fueyo, J., Xu, J., Conrad, C. A., Aldape, K. D., de Groot, J. F., Bekele, B. N., and Yung, W. K. (2008) Neuro. Oncol. 10, 940-945.

[46] Gaudreault, J., Webb, W., Hoy, M. V., Hsei, J. V., Kljavin, I., Nixon, A., Reich, M., Carlson, C., Arata, A., Keller, G., and Ryan, A. (1999) Am. Assoc. Pharm.Sci. Suppl. 1, 2142.

[47] Rosenfeld, P. J., Brown, D. M., Heier, J. S., Boyer, D. S., Kaiser, P. K., Chung, C. Y., and Kim, R. Y.; MARINA Study Group. (2006) N. Engl. J. Med. 355, 1419-1431.

[48] Lamdana, H., Ayalaa, M., Rojasa, G., Munoza, Y., Moreraa, Y., Guirolab, O., Chineab, G., and Gavilondoa, J. V. (2011) J. Biotechnol. 151, 166-174.

[49] Yu, Y., Lee, P., Ke, Y., Zhang, Y., Yu, Q., Jonathan Lee, J., Li, M., Song, J., Chen, J., Dai, J., Do Couto, F. J. R., An, Z., Zhu, W., and Yu, G. L. (2010) PLoS One 5, 1-12.

[50] Imai, S., Nagano, K., Yoshida, Y., Okamura, T., Yamashita, T., Abe, Y., Yoshikawa, T., Yoshioka, Y., Kamada, H., Mukai, Y., Nakagawa, S., Tsutsumi, Y., and Tsunoda, S. (2011) Biomaterials 32,162-169.

[51] Brochet, X., Lefranc, M.-P., and Giudicelli, V. (2008) Nucl. Acids Res. 36, 503-508.

[52] Seker, U. O. S., Wilson, B., Dincer, S., Kim, I. W., Oren, E. E., Evans, J. E., Tamerler, C., and Sarikaya, M. (2007) Langmuir 23, 7895-7900.

[53] Zhu, Z., Rockwell, P., Lu, D., Kotanides, H., Pytowski, B., Hicklin, D. J., Bohlen, P., and Witte, L. (1998) Cancer Res. 58, 3209-3214.

[54] Kunkel, P., Ulbricht, U., Bohlen, P., Brockmann, M. A., Fillbrandt, R., Stavrou, D., Westphal, M., and Lamszus, K. (2001) Cancer Res. 61, 6624-6628.

[55] Li, R., Xiong, D. S., Shao, X. F., Liu, J., Xu, Y. F., Xu, Y. S., Liu, H. Z., Zhu, Z. P., and Yang, C. Z. (2004) Acta Pharmacol. Sin. 25, 1292-1298.

[56] Kamba, T. and McDonald, D. M. (2007) Br. J. Cancer 96, 1788-1795.

[57] Sandler, A. B., Schiller, J. H., Gray, R., Dimery, I., Brahmer, J., Samant, M., LI, W., and Johnson, D. H. (2009) J. Clin. Oncol. 27, 1405-1412.

[58] Schneider, B. P., Wang, M., Radovich, M., Sledge, G. W., Badve, S., Thor, A., Flockhart, D. A., Hancock, B., Davidson, N., Gralow, J., Dickler, M., Perez, E. A., Cobleigh, M., Shenkier, T., Edgerton, S., and Miller, K. D.; ECOG 2100. (2008) J. Clin. Oncol. 26, 4672-4678. 